\title{
Service users' perceptions of the effective ingredients in supported employment
}

Robyn Lauren Johnson, City University, London

Mike Floyd, City University, London

Doria Pilling, City University, London

Melanie Jane Boyce, Institute of Health \& Social Care, Anglia Ruskin University

Bob Grove, Sainsbury Centre for Mental Health

Jenny Secker, South Essex Partnership NHS Trust and Anglia Ruskin University

Justine Schneider, University of Nottingham and Nottinghamshire Healthcare Trust

Jan Slade, Durham University, Durham, UK

\section{Abstract}

Background: The UK government is advocating the use of supported employment to help people on incapacity benefits back to work, with an emphasis on Individual Placement and Support (IPS) models. However there is little UK-based evidence on the key ingredients of effective support.

Aim: To ascertain service users' views of what they found helpful about supported employment.

Method: Interviews were carried out with 182 people with severe and enduring mental health problems who were actively engaged with one of the six supported employment agencies included in the study.

Results: Three themes emerged: emotional support, practical assistance and a client-centred approach.

Conclusion: The findings highlight the importance of the quality of support, particularly through interpersonal dynamics, which go beyond the organizational features emphasized in the IPS model.

Declaration of interest: The study was financed from Higher Education European Social Fund Objective 3 resources and the six partner agencies made contributions in kind.

Keywords: Supported employment, Individual Placement and Support (IPS), mental illness, service users

\section{Introduction}

The UK government has recently introduced a number of measures to encourage people on incapacity benefits back to work. A key feature of its commissioning guidance is to "implement evidence-based practice within vocational services, in particular the Individual Placement and Support (IPS) approach" (Care Services Improvement Partnership, 2006, p. 3). Within IPS, employment and clinical care are seen as linked strands of the recovery process, acting separately and together to improve well-being and quality of life. The goal is competitive employment in integrated work settings, with minimal prevocational training or assessment. There is an emphasis on clients' needs and preferences, with follow up support being provided for as long as necessary. This is provided within a multidisciplinary approach where vocational and clinical support is integrated (Becker \& Drake, 2003).

Although there is evidence to support the IPS model, most of it comes from North America and there is very little UK-based research on supported employment. The research reported in this paper is part of the SESAMI (Social Inclusion through Employment Support for Adults with Mental Illness) study, one of the first studies to explore models of supported employment, including IPS, and evaluate their effectiveness across England (SESAMI Research Team, 2007).

A few studies in the United States have explored the components of supported employment. For example, Gowdy et al. (2004) interviewed programme staff and users to identify the factors that contributed to differences in employment rates between programmes. They found distinctive differences between high performing and low performing programmes, such as staff in high performing programmes holding positive views about the value of work and about clients' ability to work. However, most studies examining the factors of supported employment 
have compared client outcomes with characteristics of the service (Becker et al., 2006; Jones et al., 2001), rather than gaining stakeholders' views.

Organizations are increasingly being encouraged to actively engage service users in the evaluation and development of their services. The Department of Health, in particular, has made a commitment to this, for example in its National Service Framework (NSF) for Mental Health in 1999. Similarly, in North America, one of the major goals of the President's New Freedom Commission on Mental Health (2003) is that mental health care should be consumer and family driven.

Users of employment support programmes were central to the SESAMI study. Here we describe the helpful aspects of supported employment, as identified by service users. Ethics approval was granted for the study by the North West Multi-Centre Research Ethics Committee. The relevant NHS Trusts granted research governance approvals where applicable.

\section{Method}

\section{Agencies}

Six partner agencies participated in the study, designated here as Agencies A- F. Agency A differs from the other partner agencies in that it operates within the mental health sector. Agencies $\mathrm{B}, \mathrm{C}$ and $\mathrm{D}$ operate within the voluntary sector, by far the most common location for UK vocational services. Agency $E$ is a pan-disability organization with contracts to implement two government programmes - Workstep and New Deal for Disabled People (NDDP) - while Agency $F$ is an arm of the Department for Work and Pensions (DWP) that contracts out the Workstep programme under a range of brokerage arrangements. NDDP is delivered through advisers known as job brokers to individuals with health- or disabilityrelated barriers to labour market entry. It aims to provide career advice, practical support and guidance through the benefits maze.Workstep is designed to help people who face more complex barriers, and can provide training and ongoing support to the employer as well as the employee.

The SESAMI study also looked at the extent to which partner agencies adhere to the Supported Employment Fidelity Scale ${ }^{1}$ and the individual components of IPS (Boyce et al.,in press). Agency $A$ attained a good adherence rating, while Agencies $B, C$ and $D$ all attained a fair adherence rating. The rating for Agency $E$ indicated that this provider was not delivering supported employment based on the IPS approach. Because Agency F contracts out the Workstep programme under a range of brokerage arrangements it was not meaningful to include the agency in this aspect of the study.

\section{Procedure}

We set as our inclusion criterion the presence of severe and enduring mental health problems, judged as a score of more than three in the responses to a list of items (see The SESAMI Research Team \& Practice Partnership, 2007). The sampling frame consisted of all those with a mental health problem registered with one of the agencies. Agency staff distributed the invitation letters on behalf of the research team. Of the 888 people contacted, $340(38 \%)$ replied and 48 of these $(14 \%)$ declined to participate. The 292 who agreed to participate completed a brief screening questionnaire and $270(92 \%)$ met our criterion. Thirtytwo of these people $(12 \%)$ decided to withdraw from the study and $27(10 \%)$ did not respond to further contact. In this way, 211 participants were recruited and interviewed. Of those interviewed, 182 people (86\%) were actively engaged with one of the six agencies, and constitute the study sample.

Interviews were conducted at two time points, with approximately 12 months between each; $155(85 \%)$ were interviewed at follow up. Interviews were conducted by one of three female members of the SESAMI research team, either in a private room in the supported employment premises, or in the community (e.g., a quiet coffee shop) - whichever the client preferred. This paper draws on data that were collected during a pre-amble to a structured interview based on standardized measures. Service users were invited to comment on their 
experiences of working with the Employment Support Workers (ESWs), helpful aspects of support and ways in which it could be improved. Handwritten notes of participants' exact words were made during the interviews and typed up immediately afterwards.

\section{Data analysis}

Notes were analysed using thematic analysis, following the steps advocated by Miles and Huberman (1994). The first step was "data reduction" in which the data were summarized, followed by "data display" where matrices were used to organize notes and coding categories were developed. Notes were categorized and labelled according to themes that emerged from their content. In the final stage, conclusions were drawn and verified.

\section{Participants}

There were 106 men and 76 women and the average age was just over 42 . The majority $(80 \%)$ described themselves as White British, $11 \%$ as Asian, $3 \%$ as Black British and $3 \%$ as from "other ethnic groups". Participants had experienced mental health problems for between one and 50 years, with an average of 13.1 years. Seventy two percent had a history of being admitted to psychiatric hospital.

At Time 1, 105 participants (58\%) were unemployed, 59 (32\%) were in paid employment in competitive, real world jobs, and $18(10 \%)$ were in a work-related placement. Two unemployed people had never worked. Of the 155 who participated at follow-up, 22 unemployed participants moved into paid work during the course of the study (14\%), and three of the 14 who had been in a work placement at Time 1 also moved into work. Six people moved out of paid employment, and seven who were in a placement at Time 1 were unemployed at Time 2. At Time 1, only three people had been with their employment support agency for less than a month, 31\% for between two and six months, $29 \%$ between seven and 12 months, and $38 \%$ for over a year.

\section{Results}

Three themes relating to what service users found valuable emerged during analysis: emotional support, practical assistance and a client-centred approach. Those who moved in to paid employment or remained employed between the two interviews were generally more positive about the support they received than those who lost a job or did not obtain one, although there appeared to be no difference in the kind of support they found helpful.

\section{Emotional support}

Just under a third (30\%) of service users' responses centred on cognitive and emotional support: the help they received to stay focused, motivation and encouragement, and developing their confidence. This involved the development of a good relationship with the ESW, continuity in the relationship and the assurance that the ESW would be available when needed. It also required understanding on the part of the ESW of the problems faced by people with mental illnesses.

\section{Motivation and encouragement.}

An important aspect of support for 13 people (7\%) was that it enabled them to stay focused. They explained how it gave them a sense of purpose, and helped them to "move forward". For some, the support was evidently an integral part of their lives; it was described by one person as "one of the anchors in my life", and as "my brick" by another. One client explained how the support was imperative in his transition into work: "[The Agency] gives me a purpose more than anything else. I feel like it's part of something - a stepping stone - you can't go straight from hospital to work".

Participants also felt that the support provided a structure to their daily lives and that regular contact encouraged them to concentrate on work issues. Twelve people talked about how their ESW actively motivated them: "It was good just seeing someone, it stopped me being 
able to slack off, as every two weeks, she was cajoling me along, so that I was making some progress".

\section{Building confidence.}

A key element of good supported employment was building self-confidence. Several described how their ESW had hugely improved their confidence and helped them to believe that they were able to work and "have something to contribute". It seems this was achieved through gentle but persistent reassurance: "she was constantly bumping me up, but without pushing me..."

\section{Availability of support.}

It was important that this reassurance and encouragement was available should the service user need it. Knowing someone was there for them brought a sense of comfort and security and was one of the most frequently mentioned issues (28 people - 15\%) across all the agencies. Many were very reassured to know that their ESW was "at the end of the phone" to provide advice or help them to feel that they were "not alone". This was particularly important to people who were in work. They appreciated being able to talk through issues that may arise, especially when they felt nervous or their mental health problems affected their work.

However, some people, mostly from Agency A, felt that they did not see their support worker frequently enough, and would have appreciated telephone calls in-between meetings "just to say 'how's that going?"' Several explained that they would have preferred more organized, regular meetings to "ad hoc" appointments. These people generally saw their ESW once a month. Furthermore, a number of interviewees from the same agency reported that contact was too irregular or had stopped suddenly. In some cases this was because the ESW was leaving the job, but for others the reason was unclear; one interviewee thought that she had "done something wrong" and a few were unsure whether they had been discharged from the service.

\section{Positive relationship.}

Twenty people $(11 \%)$ commented on the good relationship they had with their ESW. The "care and commitment" shown by ESWs was integral to this. Having the same support worker enabled a supportive relationship to form and allowed the ESW to understand the service user's needs.

Informality of surroundings also aided the development of a supportive relationship. Most service users preferred having meetings in neutral environments such as a coffee shop because they felt comfortable and were able to get accustomed to different environments. In one of the agencies, where meetings were generally held on agency premises, clients appreciated the relaxed atmosphere and being able to make contact with other users. In contrast, some of those who met in more formal venues such as job centres found them to be intimidating or "scary".

\section{Practical assistance}

Over one in three service users $(38 \%)$ found the more practical types of support they had received to be extremely helpful. This included financial assistance (e.g., funding for courses or suits for interviews), help with job preparation, job searching and the application process. They also valued their ESWs' knowledge and expertise.

\section{Job preparation.}

Simply having to meet their ESW was of great help to some service users. They explained how receiving support meant that they needed to leave their house to keep appointments. Following a routine, being out in public and having "human contact" helped to improve their mental health and prepare for work. 
People also referred to their ESWs accompanying them on various work-related outings, such as job centres, the library, job fairs or driving them to interviews. This was particularly helpful if they were feeling nervous about an interview or had problems relating to social anxiety.

A large number of people $(30-16 \%)$ across all agencies talked about being helped onto a course to further their vocational aims or undertaking training arranged by the support agency, such as confidence building, job searching or interview skills. They found that not only was the content of such courses useful, but that they were able to broaden their social network and get used to following a routine. However six people, mostly from one of the voluntary sector agencies, found the training to be "patronising" or "insulting".

\section{Job searching.}

A vital component of support was being able to obtain information and advice from ESWs. Service users highly valued the knowledge base held by their ESW, for example with regards to job search websites, contacts (such as at the local job centre, or for potential employers), training and funding opportunities and employees' rights and felt they were in a good position to help them find suitable vacancies: "He knows ... what to do, when to do it, and how".

Some agencies ran job clubs or self help groups which were useful sources of information where clients had the opportunity to meet, use resources such as telephones, the internet and newspapers and help each other with the job search process. They enjoyed being able to make social contact with people in a similar situation.

Ten people found it very helpful when their ESW actively sought information on their behalf. They appreciated their ESW sending them job advertisements or information on specific posts. Participants also enjoyed simply talking through job options, and valued the opportunity to "bounce ideas around".

They also welcomed their ESWs' suggestions and ideas, who they explained, were able to be objective and propose different avenues. However, 10 felt that their ESW did not have sufficient knowledge or experience to cater for their vocational aims, for example in computerrelated work or work in animal care, or certain issues such as self-employment or welfare benefits.

\section{The application and recruitment process.}

One of the most frequent responses, cited by 34 people (19\%), focused on assistance with constructing, updating and editing Curriculum Vitaes and completing application forms. Many also pointed to the help they had received with preparing for interviews as a vital characteristic of support. "Mock" or practice interviews were very much appreciated, as was talking to the client immediately prior to the interview to help them to relax or "warm up": "I was scared by the thought of interviews - she helped me to work out what to say . . . what's relevant".Moreover, people were reassured that they could turn to their ESW for advice on various work-related queries such as benefits, disclosing their mental health problem and occupational health assessments.

The value of links with employers was also recognized across agencies. Three clients welcomed the "mediator" role held by their ESW, particularly at the beginning of employment. For example, one person explained how his ESW had helped his employer to understand his mental health problems. Another three suggested that their support agency could develop more links with local employers, for example through workshops to increase organizations' awareness of mental health problems.

\section{Client-centred approach}

Twenty people (11\%) commented on the way in which the support was provided. "Letting the client lead" was a much valued approach, as one service user described: "The ethos is about the client and finding out what they want to do to improve things in their lives". The crucial elements here appeared to be tailored support and appropriate job matching. 


\section{Tailored support.}

A key theme was providing an appropriate level of support at the right pace. Fourteen participants were very grateful that they had not experienced any pressure to do more than they felt ready for and were "allowed to take things a stage at a time". It was important to "go at a pace the client is comfortable with". However, a few people felt that they had been rushed into paid work and some ESWs were described as being "pushy".

It was important, though, to provide enough active support; the biggest criticism voiced by interviewees centred round a need for more intensive support. Interviewees from all agencies expressed a desire for support that was more "direct" or "active". They talked about being left to their own devices, where the onus was on the individual to be proactive.

They also highlighted, however, that it was important that their ESWs facilitated and guided the process rather than dictating what should be done and how: "They didn't tell me things, they suggested it. They asked me if I would like to ... and then I did it for me".

\section{Appropriate job matching.}

Another significant issue was understanding service users' needs and abilities, and matching their experience to appropriate jobs. This involved listening to clients, understanding what they were saying, exploring their strengths and weaknesses and being aware of their needs. In some cases, this appeared to be lacking and some ESWs were reported to pursue unsuitable job leads. Rather, people wanted help to set realistic goals and to think about "what's achievable".

Having their interests and abilities recognized enabled effective discussion around job choice and career options. Nine participants appreciated their ESW helping them to think about what sort of job they wanted to do, particularly in relation to long-term career aims: "[My ESW] and the team persuaded me to do something I really want to do, not just do something for the sake of it so they advised me to retrain".

\section{Joint working.}

Agency A works within community mental health teams and in some cases meetings were held with the client, ESW, and another member of the community mental health team (normally a Community Psychiatric Nurse (CPN) or occupational therapist). Five out of six people mentioning these meetings were positive about them, generally because it helped to ensure cohesion amongst their different sources of support. Also, their ESW was able to have a say in decision-making regarding treatment:

She [my ESW] had a good relationship with my CPN and sometimes I saw them together. I found this helpful and sometimes [ESW] veered him [CPN] away from thinking about me staying in hospital when things were difficult. .., she would say that she thought employment would be better for me. She spoke for me because I also thought working would be better for me. They didn't argue but they bounced off each other.

\section{Discussion}

There are two main limitations with this aspect of the SESAMI study. First, analysis was conducted from handwritten notes rather than audio tapes. However, the researchers recorded detailed notes, which were verbatim as far as possible and typed up the notes as soon as possible after the interviews. The researchers were confident that the notes accurately reflected interviewees' views. Second, although some writers advocate the use of consensus coding or other methods to strengthen the reliability of qualitative analysis, time and resource pressures precluded such an approach and the lead author carried out the analysis. However, an early draft of the analysis, including a great deal of the data from which the themes were derived, was read by all members of the SESAMI team in order to check the 
validity of the interpretations. This resulted in some rethinking and restructuring of the analysis.

The findings endorse many aspects of IPS, such as "finding a job that matches the client's interest, skills and unique qualities" (Becker \& Drake, 2003, p. 23) and tailoring support. However, the results highlight the importance of the quality of the support, particularly through interpersonal dynamics and go beyond the organizational features that seem to be stressed in the Supported Employment Fidelity Scale. For example, the scale does not cover the extent to which ESWs are available to service users, or how much time the ESW spends on building service users' self-confidence or encouraging them. It would appear that such factors are vital components of the job search process from the client's perspective and should arguably be included amongst the key ingredients of effective support.

\section{Note}

$1 \quad$ The fidelity scale is a 15-item assessment instrument developed by Becker and Drake (2003) (see also Bond et al., 1997), which further isolates the active ingredients of IPS. It measures the extent to which employment support agencies adhere to the various elements of IPS, such as the lack of eligibility criteria, relatively small caseloads, short time between referral and job search, close integration between employment and mental health services, low percentage of clients who are in the same job setting or type, continuity of employment specialists and unlimited outreach if clients disengage with the service.

\section{References}

Becker, D. R., \& Drake, R. E. (2003). A working life for people with severe mental illness. Oxford, UK: Oxford University Press.

Becker, D., Xie, H., McHugo, G., Halliday, J., \& Martinez, R. (2006). What predicts supported employment program outcomes? Community Mental Health Journal, 42, $303-312$.

Bond, G. R., Becker, D. R., Drake, R. E., \& Vogler, K. M. (1997). A fidelity scale for the Individual Placement and Support model of supported employment. Rehabilitation Counseling Bulletin, 40, $265-284$.

Boyce, M., Secker, J., Floyd, M., Grove, B., Johnson, R., Schneider, J., et al. (2006). Factors influencing the delivery of evidence-based supported employment in England. Psychiatric Rehabilitation Journal, in press.

Care Services Improvement Partnership (2006). Vocational services for people with severe mental health problems: Commissioning guidance. London: National Institute for Mental Health England.

Department of Health (1999). National Service Framework for Mental Health: modern standards and service models. Retrieved 19 January 2007 from: http://www.dh.gov.uk/PublicationsAndStatistics/Publications/PublicationsPolicyAndGuidance/ PublicationsPolicyAndGuidanceArticle/fs/en?CONTENT ID1/44009598\&chk1/4jmAMLk

Gowdy, A., Carlson, L., \& Rapp, C. (2004). Organizational factors differentiating high performing from low performing supported employment programs. Psychiatric Rehabilitation Journal, 28, $150-156$.

Jones, C., Perkins, D., \& Born, D. (2001). Predicting work outcomes and service use in supported employment services for persons with psychiatric disabilities. Psychiatric Rehabilitation Journal, 251, $53-59$.

Miles, M. B., \& Huberman, A. M. (1994). Qualitative data analysis: An expanded sourcebook, 2nd edn. Thousand Oaks, CA: Sage. 
New Freedom Commission on Mental Health. (2003). Achieving the promise: Transforming mental health care in America. Final Report. DHHS Pub. No. SMA-03-3832. Rockville, MD. $\begin{array}{llll}\text { Retrieved } & 19 & \text { January } & 2007\end{array}$ http://www.mentalhealthcommission.gov/reports/Finalreport/FullReport.htm

The SESAMI Research Team \& Practice Partnership (2007). The SESAMI evaluation of employment support in the UK: Background and baseline data. Journal of Mental Health, 16, $375-387$ 